\title{
0 licenciamento ambiental como política pública e o poder das empresas
}

\author{
Recibido: 6 de diciembre de 2018 • Aprobado: 3 de agosto de 2019 \\ https://doi.org/10.22395/ojum.v19n38a4 \\ Victor Rizo Schiavo* \\ Elda Coelho de Azevedo Bussinguer ${ }^{* * *}$
}

\begin{abstract}
RESUMO
O presente estudo destina-se a apresentar o Licenciamento Ambiental como uma Política Pública de Estado e um instrumento capaz de avaliar tecnicamente a atividade empresarial diante do discurso do crescimento econômico. Nesse contexto, após a Convenção de Estocolmo com o forte sentimento ambiental instituído pelo mundo e, consequentemente, com a edição da legislação específica na área ambiental do Brasil, as empresas tiveram que subordinar suas atividades ao Estado. Com isso, confrontaremos o Direito ao meio ambiente ecologicamente equilibrado e o Desenvolvimento econômico, ambos presentes na Constituição da República Federativa do Brasil de 1988, em contrapartida aos fundamentos da teoria do poder de Foucault.
\end{abstract}

Palauras-chave: Constituição Federal; política pública; licenciamento ambiental; poder; meio ambiente.

* Artigo desenvolvido no Grupo de Estudos, Pesquisa e Extensão em Políticas Públicas, Direito à saúde e Bioética (Biogepe) da Faculdade de Direito de Vitória (FDV).

** Mestrando em Direitos e Garantias Fundamentais da Faculdade de Direito de Vitória (PPGD-FDV). Pós-graduado em Direito Processual Civil. Pesquisador e Membro do Grupo de Estudos, Pesquisa e Extensão em Políticas Públicas, Direito à saúde e Bioética (Biogepe). Advogado. E-mail: victor rizo schiavo@hotmail.com.

*** Livre-docente pela Universidade Federal do Estado do Rio de Janeiro (UniRio). Pós-doutora em Saúde Coletiva pela Universidade Federal do Rio de Janeiro (UFRJ). Doutora em Bioética pela Universidade de Brasília (UnB). Mestre em Direitos e Garantias Fundamentais pela Faculdade de Direito de Vitória (FDV). Mestre em Enfermagem pela Universidade Federal do Rio de Janeiro (UFRJ). E-mail: elda.cab@gmail.com 


\section{El licenciamiento ambiental como políitca pública y el poder de las empresas}

\section{RESUMEN}

El estudio pretende presentar el licenciamiento ambiental como una política pública de Estado y un instrumento capaz de evaluar técnicamente la actividad empresarial ante el discurso del crecimiento económico. En este contexto, luego de la Convención de Estocolmo, con fuerte sentimiento ambiental instituido por el mundo y, por ende, con la edición de norma específica en el área ambiental de Brasil, las empresas tuvieron que subordinar sus actividades al Estado. De ahí, confrontamos el Derecho al medio ambiente ecológicamente equilibrado y el desarrollo económico, ambos presentes en la Constitución de la República Federativa de Brasil de 1988, en contrapartida a los fundamentos de la teoría del poder de Foucault.

Palabras clave: Constitución Federal; política pública; licenciamiento ambiental; poder; medio ambiente.

\section{Environmental Licensing as a Public Policy and the Power of Companies}

\section{ABSTRACT}

This study aims to present environmental licensing as a public state policy and an instrument capable of technically evaluating business activity in the face of the discourse of economic growth. In this context, after the Stockholm Convention, with the strong environmental sentiment instituted by the world and, consequently, with the issue of specific legislation in the environmental area of Brazil, companies had to subordinate their activities to the State. With this situation, we confront the Right to the ecologically balanced environment and economic development, both present in Constitution of the Federative Republic of Brazil of 1988, in contrast to the foundations of Foucault's theory of power.

Keywords: Federal Constitution; public policy; environmental licensing; power; environment. 


\section{INTRODUÇÃOO}

O Direito Ambiental no Brasil, anterior à Constituição Federal de 1988 (CF/1988), possuía uma legislação fragmentada, e ainda não tinha vigor e nem um sentimento social instituído no meio da população. Dessa maneira, vê-se que a legislação era até então frágil, no sentido de proteção e equilíbrio ecológico. Nesse período, de 1934 até a concepção da CF/1988, os bens tutelados pela legislação eram água, solo, fauna e florestas. Cumpre salientar que o direito de propriedade tinha força e, nesse sentido, prevaleciam as intenções da iniciativa das empresas sobre a proteção do meio ambiente.

Com o crescimento industrial mundial, e com os altos índices de poluição do meio ambiente, surgiu uma preocupação em ter algum instrumento formal de garantia e proteção do meio ambiente que pudesse envolver o máximo de países possível. Em 1972, na Convenção de Estocolmo, a preocupação e a finalidade eram fomentar o surgimento de legislações de proteção ao meio ambiente pelo mundo. Mais do que isso, foi um instrumento de grande valor, uma vez que incentivou o sentimento da população com respeito à proteção ambiental.

Em 1981, o Brasil editou a Política Nacional do Meio Ambiente que deu uma nova roupagem à legislação ambiental no país e começou a utilizar as políticas públicas para a proteção do meio ambiente.

Dessa forma, em 1988, foi promulgada a Constituição Federal, conhecida como um instrumento de cidadania que outorga os direitos fundamentais da vida humana. Dentro dessa perspectiva de proteção, ainda influenciada pela Convenção de Estocolmo, editou-se o artigo 225 que deixou claro: "Todos têm direito ao meio ambiente ecologicamente equilibrado, sendo responsabilidade do poder público e também da coletividade a sua proteção." Nesse momento, nasceu a preocupação com as presentes e também as futuras gerações, algo que até 1988 não tinha sido fomentado dentro da sociedade.

O artigo 225 da CF/1988 é exatamente uma transcrição do princípio 1 da Convenção de Estocolmo, de onde surge a primeira indagação: a Constituição Federal de 1988 foi um instrumento inovador de garantias que trouxe um sentimento para a população brasileira ou foi uma carta de obrigação que deixa claro para a sociedade que existe algo que trata do assunto?

Neste contexto de proteção, em 1997, pautado pela Política Nacional de Meio Ambiente (PNMA) em seu artigo 10, ocorreu a edição da Resolução 237 do Conselho Nacional do Meio Ambiente (Conama) que definiu as coordenadas para o Licenciamento Ambiental no Brasil. Ademais, a Política Pública instituída teve a finalidade de autorizar e avaliar as atividades ambientais industriais potencialmente poluidoras no país. 
Por muitos anos, o Brasil teve a intenção de fomentar a abertura de novas empresas a fim de acelerar o crescimento da economia e a geração de empregos. Dessa forma, os cuidados básicos necessários com o meio ambiente não foram levados em consideração. Com isso, as empresas e a iniciativa privada tomaram forças diante do Estado e até hoje têm uma relação de poder diante dos mecanismos de controle ambiental.

Ainda, a indagação da pesquisa se pauta no fato de que as empresas com grande poder econômico e com forte discurso de crescimento e geração de empregos usam desse poder para a liberação do Licenciamento Ambiental de atividade potencialmente poluidora. Então, o Licenciamento Ambiental é uma política pública eficaz para a garantia de proteção ao meio ambiente por meio desse poder que as empresas exercem durante o processo administrativo?

Dessa maneira, essa pesquisa se faz necessária ao questionar o real papel do Licenciamento Ambiental, criado pela Política Nacional do Meio Ambiente e regulamentada em 1997 pelo Conama. A investigação será pautada na Teoria do Poder do filósofo Michel Foucault, que relacionará se o sentimento ambiental advindo da Constituição Federal de 1988 conseguiu transparecer no Licenciamento Ambiental diante do poder das empresas.

Como objetivo macro, estudaremos o Licenciamento Ambiental como Política Pública de garantia ao meio ambiente ante ao poder que as empresas exercem durante o processo administrativo que autoriza tal licenciamento, com base na teoria de Michel Foucault. Além disso, o Licenciamento Ambiental será analisado como uma Política Pública de garantia do Direito ao Meio Ambiente no Brasil e se essa ferramente atende aos anseios contidos no artigo 225 da Constituição Federal.

Quanto à metodologia de pesquisa do presente trabalho, pretende-se utilizar a pesquisa bibliográfica como fonte primária de conceitos essenciais para a construção de um conhecimento capaz de promover uma análise crítica acerca do tema proposto. Assim, buscaremos fontes secundárias, especialmente publicações como livros, estudos acadêmicos e artigos que abarquem a questão central desse estudo.

Para tanto, será utilizado o método dialético, por ser um método que reconhece a sociedade como um conjunto de contradições. Dessa forma, o resultado da pesquisa demonstrará justamente que a realidade é contraditória e, por isso, sempre se está em busca de uma resposta mais adequada ao contexto social, político e econômico.

Outrossim, destina-se a estudar o atual cenário do Direito Ambiental brasileiro estritamente relacionado ao Licenciamento Ambiental como uma política pública de garantia. Pretende-se tratar brevemente a questão histórica e filosófica e os direitos fundamentais relativos ao Direito Ambiental, a Constituição Federal em seu artigo 225, e também as legislações relativas ao tema, que são a Política Nacional do Meio Ambiente (PNMA) e a Resolução Conama 237. 


\section{0 LICENCIAMENTO AMBIENTAL COMO POLÍTICA PÚBLICA}

Com o sentimento ambiental da década de 1980, tem-se no Brasil, em 1981, um marco historicamente relevante para o cenário das políticas públicas relativas ao meio ambiente. Surge a Política Nacional do Meio Ambiente, que traz uma visão globalizada sobre o meio ambiente. Deve-se esse ganho normativo ambiental à Convenção de Estocolmo, realizada em 1972, e que estimulou o sentimento ambiental pelo mundo.

A Política Nacional do Meio Ambiente trouxe a lume a tutela do meio natural e seus componentes bióticos e abióticos de forma globalizada e não mais individualizada de acordo com os benefícios trazidos para o ser humano. Mas ainda se discute apenas o meio ambiente natural. (Abreu e Bussinguer, 2013)

Quando se fala da Política Nacional do Meio Ambiente, tem-se por principal objetivo a precaução e a melhor qualidade ambiental favorável à vida. No mesmo panorama, percebe-se que a dignidade da pessoa humana é ponto de destaque no texto e traz para o país melhores condições ao desenvolvimento socioeconômico, aos interesses da segurança nacional (Brasil, 1981).

Dessa forma, percebe-se que antes mesmo da promulgação da Constituição Federal, que aconteceu apenas em 1988, o Brasil já trazia uma visão voltada à preservação do meio ambiente, construída por meio de uma política com abrangência nacional.

Logo em seguida, a Constituição Federal trouxe para a legislação brasileira o entendimento do princípio 1 da Convenção de Estocolmo e colocou o direito ambiental como obrigação e dever de todos, principalmente do Poder Público, que deve destinar seus cuidados à preservação e atenção especial em suas políticas públicas ambientais.

225. Todos têm direito ao meio ambiente ecologicamente equilibrado, bem de uso comum do povo e essencial à sadia qualidade de vida, impondo-se ao Poder Público e à coletividade o dever de defendê-lo e preservá-lo para as presentes e futuras gerações. (Brasil, 1988)

O artigo supracitado da Constituição Federal mostra que "o meio ambiente se consagrou definitivamente como um direito fundamental da pessoa humana ao classificá-lo bem de uso comum do povo e essencial à qualidade de vida" (Farias, Coutinho e Melo, 2015, p. 41-42).

Contudo, o Licenciamento Ambiental, previsto na Política Nacional do Meio Ambiente, só trouxe a regulamentação desse sistema em 1997 com a edição da Resolução Conama 237/1997. Nesse cenário, o instrumento do Licenciamento Ambiental é processo de autoria da esfera privada que deve ser fiscalizado, monitorado e liberado pela administração pública como forma de resguardar o meio ambiente (Brasil, 1997). 
É importante considerar, conforme Faria (2003), que as políticas são uma disputa entre formas de discurso baseadas na luta pelo poder e na busca de significado. Os sistemas de ideias constroem os interesses dos tomadores de decisões. Dessa maneira, deve-se atentar com o destino dessas políticas públicas ambientais no sentido de que elas possam se envolver com o interesse do Estado e o poder do governante (Faria, 2003).

Assim, a política pública atua como instrumento estatal para definir programas e ações que serão desenvolvidos a fim de garantir e colocar em prática direitos que são previstos no ordenamento jurídico e nos preceitos éticos e morais que regem um país.

Porém, vai muito além apenas da relação Estado-Sociedade, e sim da SociedadeEstado, que define as medidas e os programas criados pelo governo e dedicados a garantir o bem-estar da população. Não é viável que as políticas públicas sejam instrumentos de coerção ou até mesmo de manutenção do Estado sobre a sociedade, pois devem ser um instrumento de satisfação dos anseios da população diante das necessidades emergentes.

Além da viabilidade de assuntos sociais, as políticas públicas respondem a outros princípios que não constam apenas na lei, mas podem vir a serem problemas sociais. Pode ser advindo de direitos que, com o passar do tempo, tornam-se parte integrante de uma nação e preceitos éticos e morais da sociedade atual.

No caso do Direito Ambiental não é diferente. Existem necessidades nessa esfera que precisam de cuidados e um olhar mais especifico da legislação e do fiscalizador. Conforme a Convenção de Estocolmo previa, o sentimento ambiental estimulado em todo mundo deveria trazer legislações que garantissem o cuidado com o meio ambiente (Padilha, 2010, p. 102).

Para entender a formação e a concepção das políticas públicas pelo Estado, deve-se primeiramente analisar em que cenário elas se enquadram dentro das prioridades de um sistema. Um Sistema de Governo tem pontos distintos que são fundamentais para a formulação das suas atividades. Logo, encontramos o macrossistema, o microssistema e os subsistemas que compõem o sistema político (Capella e Brasil, 2015).

Primeiramente, o macrossistema é destinado às decisões que estão ligadas diretamente a uma política pública ou a uma estrutura de poder em torno dela. Nesse cenário estão em pauta as decisões que envolvem prioridades políticas de um governo, envolvem as questões macroeconômicas, os cortes orçamentários, entre outros. No macrosistema, tem-se alta visibilidade da população com um olhar atento para essas decisões tomadas, pois afetam diretamente o quadro social e econômico (Capella e Brasil, 2015). 
No microssistema, observa-se um cenário que não desperta muito a atenção da população. Isso se deve à alta complexidade técnica. É formado por profissionais técnicos que se destinam a formular questões em um processo de decisão centralizado e praticamente invisível socialmente (Capella e Brasil, 2015).

Por fim, ainda nas perspectivas de política de governo, observa-se que entre o macrossistema e o microssistema existe uma categoria denominada "subsistema". Essa categoria apresenta um número limitado de pessoas que atuam em instituições. Elas são especializadas e concentram seus esforços em algumas questões específicas relacionadas a uma política.

Como resultado da divisão do trabalho e da especialização da burocracia, as áreas funcionais, como educação, saúde, transporte, meio ambiente, entre outras, são compostas de arranjos institucionais e atores que tendem a se aglutinar em torno de programas ou interesses específicos. (Capella e Brasil, 2015, grifo nosso)

Desse modo, as questões ambientais estão enquadradas em um subsistema de política da administração pública. Principalmente a questão do Licenciamento Ambiental, que deve ser tratada de forma específica por profissionais que são técnicos e estão aptos a liberar o uso à esfera privada.

Cumpre salientar que o Licenciamento Ambiental previsto na PNMA é objeto obrigatório de observação do Estado e está pautado em legislação com abrangência nacional. Tem perspectiva de política pública e é definido como parâmetros do Estado para cumprimento do artigo 225 da Constituição Federal. Não cabe ao Estado a opção de cumpri-lo, mas sim o dever da aplicação e da fiscalização de novos empreendimentos.

\section{PROCESSO ADMINISTRATIVO DE LICENCIAMENTO AMBIENTAL}

O processo administrativo de Licenciamento Ambiental deve atender todos os requisitos e os anseios do artigo 225 da Constituição Federal, que estipulou como dever do Estado proteger os bens ambientais.

O Licenciamento Ambiental se constitui em instrumento de Estado para fazer a mediação entre os interesses da coletividade e os interesses de empreendedores desejosos de construir infra-estrutura ou desenvolver produtos industriais, guardando relação direta com a emergência da nova esfera pública apresentada por Habermas (1984). Requisito legal que antecede a instalação de atividades poluidoras, as que utilizam recursos ambientais ou com potencial de causar degradação ambiental, o Licenciamento Ambiental é um instrumento que busca proteger o meio ambiente de danos irreversíveis ou identificar arranjos através dos quais os danos ambientais possam ser evitados, mitigados e/ou compensados. (Souza e Jacobi, 2011)

O Licenciamento Ambiental como ato administrativo é previsto com a finalidade de investigar a atividade do empreendimento a ser instalado e avaliar os possíveis impactos que essa atividade poderá causar ao meio ambiente. É um instrumento 
técnico de avaliação e prevê, com seus estudos e avaliações técnicas, possíveis desastres ambientais.

Esse processo de Licenciamento Ambiental consiste em três etapas básicas que devem ser observadas pela administração pública responsável pelo procedimento. Essas etapas consistem na Licença Prévia, na Licença de Instalação e na Licença de Operação.

A Licença Prévia é aquela que antecede toda e qualquer atividade da futura empresa. É o passo inicial que o empreendedor deve dar para instalar o seu empreendimento. Sua finalidade é planejar e analisar a localização e a viabilidade ambiental. Ela estabelece os requisitos básicos e as condicionantes que o responsável pela atividade deverá observar para prosseguir com a instalação (Padilha, 2010, p. 153).

No segundo momento do processo de Licenciamento Ambiental, têm-se a Licença de Instalação. Coloca-se em segundo momento, pois ela é posterior à Licença Prévia e só é concedida se as condicionantes da primeira forem cumpridas. Ela autoriza a instalação do empreendimento de acordo com as especificações já definidas nos planos e programas aprovados. Ela traça medidas de controle ambiental e também define condicionantes para serem cumpridas durante esse processo (Padilha, 2010, p. 153).

Por fim, a Licença de Operação é a última fase desse processo administrativo. É a fase em que será autorizada a operação da empresa e o início das atividades. Ela só é concedida após a avaliação das licenças anteriores e o cumprimento de todas as condicionantes. É importante ressaltar que essa licença contém os planos de controle ambiental que devem ser base dessa nova atividade e, por isso, seu prazo de validade é de, no mínimo, quatro anos e, no máximo, dez anos, e requer a renovação mediante novos estudos (Padilha, 2010, p. 154).

O Licenciamento Ambiental se configura enquanto processo através do qual o Estado convoca as expertises técnicas (Estudo de Impacto Ambiental) de que dispõe, por um lado, e a cidadania (Audiências Públicas), por outro, para de maneira racional, dentro de um processo político, decidir sobre a conveniência ou não da instalação de determinado arranjo produtivo. O Licenciamento Ambiental trata, precisamente, da possibilidade que a sociedade tem de produzir; sem, contudo comprometer os serviços ambientais e as condições para o prosseguimento das diversas formas de vida. (Souza e Jacobi, 2011)

Durante esse processo administrativo, a Resolução Conama 237/97 prevê alguns requisitos básicos que devem ser observados. Entre eles, um importante instrumento é o da Audiência Pública, que visa o esclarecimento de possíveis falhas da futura atividade a ser instalada.

A Audiência Pública é o estágio do processo de Licenciamento Ambiental em que a sociedade pode alcançar explicações e esclarecimentos sobre as características e 
impactos da futura atividade e que são demonstradas por meio da apresentação do Relatório de Impacto Ambiental (Rima).

O Rima se trata de um resumo em linguagem simplificada do Estudo de Impacto Ambiental (EIA) e deve ser elaborado pelo empreendedor. É o momento em que o empreendedor deve recolher possíveis críticas e sugestões sobre o seu projeto (Lafetá, 2016 ).

Nesse contexto, encontra-se base legal para a obrigatoriedade da Audiência Pública de novas atividades na própria Constituição Federal, a partir do artigo 225, em seu parágrafo $1^{\circ}$, inciso IV, que prevê a obrigação de publicidade das informações referentes a atividades com potencial capacidade de poluição e degradação do meio ambiente:

Art. $225(\ldots)$

$\S 1^{\circ}$ Para assegurar a efetividade desse direito, incumbe ao Poder Público:

$(\ldots)$

IV — exigir, na forma da lei, para instalação de obra ou atividade potencialmente causadora de significativa degradação do meio ambiente, estudo prévio de impacto ambiental, a que se dará publicidade; (Brasil, 1988)

Além dessa previsão constitucional, a Resolução Conama 9/1987 prevê a Audiência Pública. No entanto, coloca-a como instrumento dispensável do processo de Licenciamento Ambiental. O órgão responsável pelo processo administrativo deverá requerer a sua realização quando for julgado necessário, ou quando for solicitado por entidade civil, pelo Ministério Público, ou por cinquenta ou mais cidadãos (Brasil, 1997).

Com isso, observa-se que esse importante instrumento de integração do Licenciamento Ambiental é facilmente esquecido durante o percurso, visto a falta de obrigatoriedade. Tem-se uma maior aplicação da Audiência Pública quando o Ministério Público exige para fins de avaliação da nova atividade.

Sobre este aspecto, certos empreendimentos, industriais ou não, podem ser geradores de "injustiças ambientais", na medida em que ao serem implementados, atribuem riscos e danos às as camadas mais vulneráveis da sociedade, acarretando na sua exclusão do processo de desenvolvimento. A construção de hidrelétricas, por exemplo, que ocupa grandes extensões territoriais, quase sempre transferindo os prejuízos aos segmentos sociais vulneráveis, tais como a populações ribeirinhas e comunidades étnicas, tem gerado custos pelos impactos socioambientais que incidem diretamente sobre essas comunidades locais. Ou seja, nessas comunidades os seus atores sociais não são considerados sujeitos ativos no processo de decisão sobre os usos dos recursos naturais ali existentes. (Silveira e Araujo Neto, 2014)

Como pode ser percebido, a Audiência Pública deve ser um ato indispensável ao processo de Licenciamento Ambiental como forma de evitar o distanciamento 
da atividade empresarial com a sociedade local. Muitos empreendimentos não têm sua visão social e incumbem a sociedade apenas sua visão econômica de geração de emprego e renda local. Destarte, as Audiências Públicas têm sua devida importância, pois levam à sociedade e aos interessados, de forma sucinta e inclusiva, todas as respostas e esclarecimentos pertinentes à atividade, e garantem, assim, que todos possam entender e aceitar de forma positiva o que lhes é apresentado (Lafetá, 2016).

Ressalta-se que uma Audiência Pública, prevista legalmente, deve ser capaz de tirar as dúvidas e acabar com os receios da sociedade e interessados quanto à atividade que se pretende iniciar. Se isso não for possível, pode acarretar sérios problemas, inclusive o indeferimento do pedido de sua licença ambiental (Lafetá, 2016).

O que deixa essa importante etapa do Licenciamento Ambiental esquecida é a falta de obrigatoriedade, uma vez que alguns estados têm suas regulamentações próprias. Contudo, a Resolução Conama 9/1987 ainda é de suma importância no cenário nacional e também serve como base para a elaboração das normas legais estaduais e até mesmo municipais referentes ao procedimento administrativo (Lafetá, 2016 ).

É preciso que as Audiências Públicas sejam consideradas com sua devida importância. Conforme a própria Constituição Federal prevê, deve ser levado tanto à sociedade quanto ao estado o resguardo dos bens ambientais para as presente $\mathrm{e}$ futuras gerações.

\section{3. $O$ LICENCIAMENTO AMBIENTAL X PODER DAS EMPRESAS}

Existe uma grande ligação entre a operação de novas empresas e o cenário econômico local e nacional do país. Diante da necessidade de movimentação econômica e geração de empregos, tem-se o comprometimento do processo de Licenciamento Ambiental, que já se inicia tendenciosamente ao lado positivo.

Nesse contexto, a divulgação de notícias que visa o desenvolvimento coloca em risco o procedimento que deve ser totalmente técnico. Um exemplo disso é o caso que envolve uma das maiores empresas exploradoras de minério do país. Em 2015, a Samarco foi responsável pelo maior desastre ambiental nacional. Devido ao seu alto poder econômico e ao seu discurso de geração de emprego e renda, colocou em risco o meio ambiente e toda uma sociedade fragilizada.

No ano de 2017, que foi o ano da renovação do Licenciamento da Samarco, uma das etapas desse processo foi a Audiência Pública exigida pelo Ministério Público (Samarco, 2017). Cumpre salientar que essa audiência foi solicitada devido ao desastre acontecido no ano de 2015, em que várias famílias foram atingidas. Caso não fosse exigida pelo MP talvez nem existisse esse momento com a sociedade. 
No fôlder de convite à sociedade, publicado no site da empresa, constam os dados informativos do licenciamento proposto para o retorno das atividades operacionais, e juntamente, as informações da geração de emprego e dos dados de faturamento e produção no cenário nacional. Percebe-se que o processo torna-se viciado a partir desse momento, pois confronta dados econômicos e financeiros com os estudos para autorização das atividades da empresa.

A questão do desenvolvimento do país entra em confronto com a legislação ambiental e coloca esta como impedimento para o avanço daquela. Essa questão é assunto constitucional e é colocado como um fim ao qual o Estado Democrático deve observar. A referência do termo "desenvolvimento" é objetivo fundamental do Estado brasileiro, conforme consta no art. $3^{\circ}$ da CF:

Art. $3^{\circ}$ Constituem objetivos fundamentais da República Federativa do Brasil:

I - construir uma sociedade livre, justa e solidária;

II - garantir o desenvolvimento nacional;

III - erradicar a pobreza e a marginalização e reduzir as desigualdades sociais e regionais;

IV - promover o bem de todos, sem preconceitos de origem, raça, sexo, cor, idade e quaisquer outras formas de discriminação. (Brasil, 1988, grifo nosso)

Além dessa citação constitucional, tem-se no art. 21, IX, da própria CF, que é competência da União "elaborar e executar planos nacionais e regionais de ordenação do território e de desenvolvimento econômico e social" (Brasil, 1988).

Nesse contexto, observa-se o confronto de dois princípios, digam-se fundamentais, ao Estado Democrático de Direito. O primeiro apresenta-se como visão para o Estado, que deve ter suas atividades voltadas para o desenvolvimento, enquanto o segundo coloca-se como proteção do meio ambiente ecologicamente equilibrado para todos, em uma perspectiva presente e futura.

Dessa forma, predominou no Brasil, até a Constituição Federal de 1988, a desproteção ambiental e uma visão privatista do direito de propriedade, o que constituiu uma barreira muito grande para a atuação do Estado (Padilha, 2010, p. 102).

Nesse sentido, surge um caráter estatal de crescimento econômico e também de fiscalizar as atividades que, até a edição da CF/1988 não dependiam de uma avaliação prévia antes de ser instalada. A preocupação com o meio ambiente torna-se latente dentro da sociedade brasileira.

Licenciamento Ambiental é expressão do exercício do poder de polícia ambiental, que se fundamenta na primazia do interesse público sobre o interesse particular, e sobreleva de importância no controle de toda atividade que interfere na qualidade do meio ambiente, enquanto um bem jurídico de natureza difusa e titularidade coletiva. (Padilha, 2010, p. 148) 
Em 1988, com a promulgação da Constituição Federal, surge uma preocupação em preservar o meio ambiente não apenas para as presentes gerações, mas também para as posteriores, conforme definição do art. 225, e é isso que a resolução Conama, baseada na PNMA, trouxe para o setor industrial/empresarial, que é uma preocupação em fiscalizar as atividades que possam causar uma degradação/poluição do meio ambiente, tanto no presente quanto no futuro, e prejudicar as demais gerações do planeta.

Vê-se que além de ter uma caracterização local, no âmbito do Brasil, o Licenciamento Ambiental, em uma visão macro, atenderia aos anseios da Convenção de Estocolmo, que aponta uma preocupação com a preservação ambiental dentro de um contexto universal.

Porém, antes da Convenção de Estocolmo, sem a PNMA e sem a Promulgação da Constituição Federal brasileira, as empresas não contavam com uma fiscalização sobre as atividades que exerciam (Padilha, 2010, p. 102).

Com esse novo cenário, em que o Estado assume o seu poder de polícia em fiscalizar as atividades potencialmente poluidoras, as empresas encontram novos limites para sua atuação. De um lado o Estado, com uma Política Pública de Estado, que usa o Licenciamento Ambiental para exercer a fiscalização e, no outro polo, as empresas que até então controlavam suas próprias atividades e tinham que se submeter ao processo administrativo para liberação de suas atividades.

Nesse contexto, as empresas tinham forte ação dentro do Estado brasileiro, sem restrição de suas atividades no que tange ao controle ambiental. Com o advento dessa legislação de controle às atividades, o setor empresarial, consequentemente, foi atingido.

Dessa forma, as empresas não podiam deixar de exercer suas atividades e nem o Estado podia deixar de fiscalizar. Diante disso, as empresas começaram a exercer forte influência dentro dos processos de Licenciamento Ambiental, com vistas ao benefício e à liberação de suas atividades sem um controle eficaz do Estado.

Assim, nesse embate entre o Estado e o setor privado, surgem diversas instituições com a finalidade de pressionar o cumprimento da legislação ambiental:

O processo de formação de grandes corporações industriais e empresariais e o desequilíbrio das relações na esfera social fazem surgir instituições privadas de interesse público que passam a pressionar o Estado a tomar posições em favor do equilíbrio das relações sociais. Surge uma multiplicidade de interesses privados corporativos que se entrecruzam e se fortalecem na mesma medida em que o sistema econômico se expande e ganha complexidade. (Souza e Jacobi, 2011)

O poder exercido pelas empresas é algo latente ainda dentro da sociedade. Mesmo após a Convenção de Estocolmo, a criação da PNMA e a promulgação da 
própria Constituição Federal, que trouxe um novo cenário de preservação no país, as empresas ainda têm forte poder e isso se concretiza dentro do próprio processo de Licenciamento Ambiental. Nesse sentido, recorre-se ao entendimento do filósofo Michel Foucault, que define o que é o poder:

O que faz com que o poder se mantenha e que seja aceito é simplesmente que ele não pesa só como uma força que diz não, mas que de fato ele permeia, produz coisas, induz ao prazer, forma saber, produz discurso. Deve-se considerá-lo como uma rede, produtiva que atravessa todo o corpo social muito mais do que instância negativa que tem por função reprimir. (Foucault, 1979, p. 7-8)

O poder, como apresentado acima, é algo que está presente na sociedade como um todo, mesmo que não seja percebido. No caso do Licenciamento Ambiental, confrontar uma atividade administrativa que demanda uma total avaliação técnica com o discurso de que a autorização da atividade empresarial será beneficente para uma sociedade dependente do lucro do capital é exatamente viciar o processo com o discurso do poder.

Mais do que isso, Foucault (1999, p. 18) deixa claro que existe um jogo de estratégias que usa o discurso como base para manipulação. Isso se enquadra diretamente no assunto abordado, visto que o discurso emitido pelos interessados no resultado final do Licenciamento Ambiental é carregado de interesses e visa a manipulação daqueles que não têm o real entendimento da tecnicidade do processo.

Não é somente por esse jogo estratégico do inaudito, contudo, que o discurso pode ser analisado. Também o procedimento da "vontade de verdade" é capaz de, vestindo uma roupagem institucional, exercer sobre outros discursos uma coerção. A "vontade de verdade" opera como um legitimador das verdades postas socialmente por saberes da ciência, da pedagogia, de laboratórios, do Direito, etc. (Foucault, 1999, p. 18)

Mais do que isso, o Direito ao meio ambiente ecologicamente equilibrado é um direito constitucional fundamental que é destinado a toda uma sociedade. Ao levar em consideração o real interesse do legislador, a tensão entre desenvolvimento econômico e meio ambiente não é confrontada, pois, primeiramente, temos o meio ambiente como base para uma produção nacional e para o futuro de uma geração.

Nesse sentido, é possível perceber que a subordinação ambiental é sub-reptícia e orientada principalmente por interesses hegemônicos das sociedades ocidentais, destinados a manter as condições de sobrevivência do modo de produção capitalista. É nesse contexto que a expressão "desenvolvimento sustentável", ainda que inicialmente cunhada como alternativa aos limites do crescimento econômico, serve antes à manutenção dos ideais de sobrevivência da ordem capitalista globalizada, estabelecendo um contínuo e permanente diálogo com a realidade por meio do qual sinaliza e alimenta, social e institucionalmente, a subordinação da proteção ambiental ao desenvolvimento econômico e lembrando, a todo o momento, que a proteção ambiental encontra limites claros e precisos, estabelecidos pelas perdas e ganhos do capital. (Bussinguer, Cordeiro e Salles, 2017) 
Apesar de todo o exposto, percebe-se que a sociedade ainda vive presa a uma visão totalmente capitalista de desenvolvimento econômico. A busca pelo lucro e pelo capital ainda é interesse do Estado. Percebe-se que os demais procedimentos que envolvem a avaliação de empresas ficam a mercê de um interesse de crescimento.

Nesse sentido, com parâmetros constitucionais, o desenvolvimento sustentável apresenta-se como freio ao interesse empresarial de crescimento e como instrumento de proteção do Estado. Une-se o avanço capitalista de produção à proteção ambiental. Crescer sem cuidar do meio ambiente é apenas produção capitalista, mas quando se tem um Estado e uma sociedade que visam o crescimento econômico com uma qualidade ambiental, ocorre um desenvolvimento que engloba a geração de renda e a proteção do meio ambiente.

Infelizmente, só será possível uma mentalidade de preservação do meio ambiente para as gerações futuras, se o ser humano passar a ter uma consciência pública em relação ao ambiente e colocar isso em prática por meio da conscientização e entender que é necessário ter uma educação ambiental (Rodrigues, 2005, p. 262). Um Estado Democrático de Direito "tem o dever de proporcionar e fomentar a participação e o envolvimento popular em tudo aquilo que abrange e permeia o direito fundamental de um meio ambiente ecologicamente equilibrado." (Lafetá, 2016 ).

\section{CONCLUSÕES}

O Licenciamento Ambiental apresenta-se como Política Pública de Estado evidenciado na Política Nacional do Meio Ambiente editada em 1981. A partir daí, considera-se que, muito além de uma opção governamental, é um instrumento que deve ser observado pelos governantes independente de interesses governamentais.

O processo administrativo de Licenciamento Ambiental é composto por três fases distintas, sejam elas, Licença Prévia, Licença de Instalação e Licença de Operação. Essas etapas devem ser cumpridas por aquele que deseja um parecer do órgão responsável para liberação de qualquer atividade econômica que envolva alguma alteração no meio ambiente. Cumpre salientar que, entre essas etapas, pode ser exigida uma Audiência Pública para que seja explicitado todo o procedimento da atividade para a sociedade e demais interessados no processo.

Porém, mesmo ao demonstrar que o Licenciamento Ambiental é um procedimento totalmente técnico e despido de qualquer interesse, existe uma grande relação com o desenvolvimento econômico do país, tema também pautado na Constituição Federal. Todavia, diante do procedimento administrativo surge um grande interesse das empresas que exercem seu alto poder de convencimento e confrontam o crescimento econômico e a geração de renda da atividade empresarial com os direitos ao meio ambiente ecologicamente equilibrado, ambos temas constitucionais, como evidenciado. 
A partir daí, surge o Desenvolvimento Sustentável, que é a capacidade de conciliar o crescimento e a expansão de novas atividades empresariais com o equilíbrio ambiental.

Como abordado no último capítulo, o Brasil, infelizmente, ainda vive um grande interesse de empresas que detêm forte influência na economia do país e colocam em risco o procedimento do Licenciamento Ambiental.

\section{REFERÊNCIAS}

Abreu, I. S., E Bussinguer, E. C. A. (2013). Antropocentrismo, Ecocentrismo e holismo: uma breve análise das escolas de pensamento ambiental. https://www.derechoycambiosocial.com/revista034/escolas_de_ pensamento_ambiental.pdf

Brasil. Lei 6.938, de 31 de agosto de 1981. Dispóe sobre a Política Nacional do Meio Ambiente, seus fins e mecanismos de formulação e aplicação, e dá outras providências. Congresso Nacional do Brasil. http://www.planalto. gov.br/ccivil_03/Leis/L6938.htm

Brasil. Constituição (1988). Constituição (da) República Federativa do Brasil.

Brasília: Senado Federal. http://www.planalto.gov.br/ccivil_03/Constituicao/Constituicao.htm

Brasil. Resolução Conama 237. (1997). Dispõe sobre critérios básicos e diretrizes gerais para o Licenciamento Ambiental. http://www2.mma.gov.br/port/conama/res/res97/res23797.html

Brasil. Resolução Conama 9. (1987). Dispõe sobre a realização de Audiências Públicas no processo de Licenciamento Ambiental. http://www2.mma.gov.br/port/conama/legiabre.cfm?codlegi=60

Bussinguer, E. C. A., Cordeiro, I. D., \& Salles, S. M. (2017). O discurso político-ideológico do "desenvolvimento sustentável": uma crítica à luz da epistemologia da linguagem e da teoria discursiva de Michel Foucault. DOI: $10.5020 / 2317-2150.2017 .5550$

Capella, A. C. N., \& Brasil, F. G. (2015). Análise de políticas públicas: uma revisão da literatura sobre o papel dos subsistemas, comunidades e redes. DOI: 10.1590/s0101-33002015000100003

Faria, C. A. P. (2003). Ideias, conhecimento e políticas públicas: Um inventário sucinto das principais vertentes analíticas recentes. Revista Brasileira de Ciências Sociais, 18(51). http://www.scielo.br/pdf/ rbcsoc/v18n51/15984

Farias, T., Coutinho, F. S. N., E Melo, G. K. R. M. M. (2015). Direito Ambiental (3 ed.). Jus PODIVM.

Foucault, M. (1999). A ordem do discurso (5 ed.). Edições Loyola.

Foucault, M. (1979). Microfísica do poder. (R. Machado, Org. e Trad.). Edições Graal.

Lafetá, F. (2016). Audiência Pública Ambiental: instrumento democrático do processo de licenciamento. https:// iusnatura.com.br/audiencia-publica-ambiental-instrumento-democratico-do-processo-delicenciamento/

Padilha, N. S. (2010). Fundamentos constitucionais do direito ambiental Brasileiro. Elsevier.

Rodrigues, M. A. (2005). Elementos de Direito Ambiental: parte geral (2 ed.). Saraiva.

Samarco. (2017). Audiências Públicas: Licenciamento Operacional Corretivo. https://www.samarco.com/noticia/ 
audiencias-publicas-licenciamento-operacional-corretivo/

Silveira, M., E Araujo Neto, D. (2014). Environmental licensing of major undertakings: possible connection between health and environment. DOI: 10.1590/1413-81232014199.20062013

Souza, A. N., E Jacobi, P. R. (2011). Licenciamento Ambiental e ampliação da cidadania: o caso da fidrelétrica de Tijuco Alto. Organ. DOI: 10.1590/S1984-92302011000200003 